\title{
Trends in recruitment into core medical training in the UK
}

\author{
Authors: Richard Butterworth, ${ }^{A}$ Nick Smallwood, ${ }^{B}$ Stephen Harding ${ }^{C}$ and David Black ${ }^{D}$
}

\begin{abstract}
The Physician Specialty Recruitment Office of the Royal College of Physicians has overseen recruitment into core medical training since 2009. This has allowed trends in recruitment numbers and the experience of applicants to be followed. Current recruitment into core training is not providing a large enough pool of trainees to sustain adequate filling of higher medical specialty training posts and therefore ultimately bridge the consultant vacancy rates in the UK.
\end{abstract}

KEYWORDS: Recruitment, medical workforce, core medical training, internal medicine training

\section{Introduction}

The recruitment of junior medical staff (core training year 1 (CT1)) into core medical training (CMT) programmes across the four nations of the UK has been coordinated by the Physician Specialty Recruitment Office (PSRO) of the Royal College of Physicians (RCP) and the Joint Royal Colleges of Physicians Training Board (JRCPTB) since 2009 with oversight from Health Education England. This coordination has ensured improvements in the utility of the process (in terms of measures of reliability, validity and educational impact), as well as offering efficiency savings in comparison to locally (hospital or regional) run recruitment processes in operation before 2009. Equally it has allowed the PSRO to monitor trends in recruitment at CT1.

This paper will document some of these trends and explore the progress of successful CT1 applicants through to higher medical specialties (ST3+) or other career options.

\section{Methods}

Recruitment for CMT posts (internal medicine training (IMT) from 2019) consists of two recruitment rounds (rounds 1 and 2) each year with interviews between January and April to facilitate an intake at CT1 the following August. The application process has been standardised across the UK consisting of a self-scoring

Authors: ${ }^{\text {A }}$ clinical lead for recruitment \& selection, Royal College of Physicians, London, UK; ${ }^{B}$ consultant in acute medicine, East Surrey Hospital, Redhill, UK; ${ }^{C}$ physician specialty recruitment office, Health

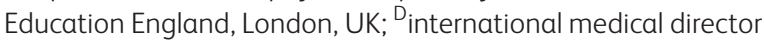
for training and development, Federation of the Royal Colleges of Physicians of the UK, London, UK application form and a multiple mini-interview assessment. The process has evolved since 2009 with measures to improve the reliability further (such as the introduction of calibration in the interview stations) and additions to the domains on the application form to maintain validity, but the central aim to fill as many CT1 posts nationally as possible with appointable candidates has not. The process is transparent throughout for candidates with clear guidance on the IMT recruitment website. From 2018 onwards, candidates have been able to list a preference for any post (or region) nationally and are ranked nationally using a single transferable score model of recruitment irrespective of their interview site.

Furthermore, the General Medical Council (GMC) has been supplying the PSRO with data on the current specialty of trainees scheduled to have completed CMT in the period of 2012-2017. This was achieved by tracking cohorts of trainees via the GMC national trainee surveys. This information has been used to then help track the subsequent progress of these CMT cohorts.

\section{Results}

Table 1 shows the comparative unique applicant totals for CMT/IMT in each of the last 7 years. In 2018, the number had increased to 2,958 , breaking a declining trend from the high of 3,180 applicants in 2014 to the low in 2017. However, a dip was seen again in 2019 (2,884 unique applicants) with the lowest number of round 1 applicants $(2,225)$ in any year. The total number of unique applications in 2019 was only maintained by a record round 2 application number, which includes applications from doctors excluded from applying in round 1 because of UK employment restrictions.

The competition ratio has stabilised at around 1.70-1.80 and is still well below figures seen prior to 2015 and can be largely attributed to the increase in the number of vacancies available in recent years, although the number of posts on offer in 2019 fell back to comparable numbers in 2014 and 2015.

The gender split for CT1 round 1 candidates over the past 6 years has been remarkably stable ( $43 \%$ male to $57 \%$ female in 2014 and $43 \%$ male to $53 \%$ female with $4 \%$ not specified in 2019$)$. This also reflects the current gender split at UK medical schools. ${ }^{2}$

Traditionally the model of career progression has been one of the seamless completion of foundation and core training competencies, followed by the similar completion of higher specialist, or general practitioner (GP), competencies. Furthermore, many trainees undertake additional training in educational or medical leadership fellowships, or complete a designated period of research, lengthening the total duration of training as outlined in the Shape of Training final report. ${ }^{3}$ 
Table 1. Overall core medical training / internal

medicine training applications per round/year and

competition ratios

\begin{tabular}{llllll} 
Year & Round 1 & Round 2 & Unique & $\begin{array}{l}\text { Unique } \\
\pm, \%\end{array}$ & $\begin{array}{l}\text { Competition } \\
\text { ratio }^{a}\end{array}$ \\
$\mathbf{2 0 1 3}$ & 2,748 & 664 & 3,118 & $\mathrm{n} / \mathrm{a}$ & 2.00 \\
$\mathbf{2 0 1 4}$ & 2,732 & 666 & 3,180 & +2 & 2.06 \\
$\mathbf{2 0 1 5}$ & 2,631 & 600 & 2,998 & -6 & 1.86 \\
$\mathbf{2 0 1 6}$ & 2,516 & 596 & 2,871 & -4 & 1.68 \\
$\mathbf{2 0 1 7}$ & 2,337 & 732 & 2,757 & -4 & 1.61 \\
$\mathbf{2 0 1 8}$ & 2,455 & 720 & 2,958 & +7 & 1.71 \\
$\mathbf{2 0 1 9}$ & 2,225 & 844 & 2,884 & -3 & 1.82 \\
\hline
\end{tabular}

$=$ The competition ratio shows the number of unique applicants / final number of vacancies across both rounds; $n / a=$ not applicable.

Data from the applicants applying at CT1 in round 1

(Table 2 ) suggests that many trainees no longer look to follow this traditional career pathway, instead opting for a break between the completion of foundation stage training and commencing CT1 training. In $2010,83 \%$ of all CT1 applicants were in a foundation programme at the time of application, but this percentage has fallen in a linear fashion every year down to less than half (44\%) by 2019 . Conversely in 2010 , only $10 \%$ of applicants had finished the foundation programme at the time of application compared to $43 \%$ by 2019 . Again, this has been a year-on-year linear trend.

The PSRO does not specifically collect data on what trainees have done between the completion of foundation competencies and application for CT1, but the trend in taking a break from the traditional training pathway is associated with a higher proportion of round 1 candidates having completed Membership of the Royal Colleges of Physicians of the United Kingdom (MRCP(UK)) Part 1 examination at the time of application in 2019 compared with 2010 (Fig 1).

The marker of the success of any recruitment process is the output, ie the number of posts filled by appointable candidates. Table 3 shows the number of posts available in both rounds 1 and 2 and the number of posts filled between 2014 and 2019. The total number of posts filled (CMT and acute care common stem-acute medicine (ACCS-AM)) was remarkably stable for the period 2014 and 2017, albeit with a fall in the fill rate percentage because of an increasing number of vacancies on offer. In contrast, recruitment in 2018 resulted in the filling of 106 more posts (7\%) compared to any of the preceding 4 years. However in 2019, 83 fewer posts were filled (vs 2018), although as fewer posts were on offer, this led to a $100 \%$ fill rate resulting in a very similar total number of posts filled to pre-2018 years. It is of course possible that if more posts were available in 2019, the final number of appointees may have been higher even with the lower applicant numbers.

The data provided by the GMC through their annual trainees' survey allows tracking of successful CT1 applicants through their 2-year CMT programme into higher specialty training or other career path. Table 4 shows the data for the cohorts expected to have completed their CMT programme from 2012 onwards at various time points thereafter. Some clarification is needed before direct conclusions can be drawn; namely in the non-training group, there is no way of knowing more specifically what these doctors are doing. There is a broad range of possibilities including working in trust posts, working overseas, in designated research or undertaking a fellowship in medical education or medical management. It is likely some will have temporarily, or even permanently, left medicine (in its broadest sense) as a career, but exact numbers are unknown.

Also, the other specialties group contains trainees switching to other specialties post-CMT with clinical oncology and radiology as common career choices.

However even with these caveats, the table reveals that from cohorts, between 1,492 and 1,678 trainees in the years 2012-2017, in the first year after the standard 2-year CMT programme, the highest transition into an ST3 programme was 711 in 2012 representing only $42.4 \%$ of that year's possible cohort. Worryingly, the parallel transitions for 2015 to 2017 were $40.2 \%$ (612 trainees), 37.9\% (603 trainees) and $32.6 \%$ (487 trainees), respectively, and data from subsequent years will ascertain if this downward trend is sustained.

Comparing the data for 1 and 2 years post standard CMT completion, for the 5 years that this is possible, there is an average addition of $14.2 \%$ (or an extra 222 trainees per year) for those entering ST3 training. From the data available, it is impossible to know the extent to which these extra trainees come from those undertaking a third year at the CMT stage to complete their competencies, or return from the non-training group. Equally in the second year post standard CMT completion, $7.2 \%$ and $8.1 \%$ of trainees on average have switched to GP or other specialty training, respectively. Although not lost from the UK medical workforce, this combination represents about 240 trainees from the original CMT cohort each year.

\begin{tabular}{|c|c|c|c|c|c|c|c|c|c|c|}
\hline & 2010 & 2011 & 2012 & 2013 & 2014 & 2015 & 2016 & 2017 & 2018 & 2019 \\
\hline Current F2 & $\begin{array}{l}83 \%, \\
2,037\end{array}$ & $\begin{array}{l}75 \%, \\
1,861\end{array}$ & $\begin{array}{l}69 \% \\
1,850\end{array}$ & $\begin{array}{l}66 \% \\
1,826\end{array}$ & $\begin{array}{l}63 \% \\
1,733\end{array}$ & $\begin{array}{l}60 \% \\
1,587\end{array}$ & $\begin{array}{l}56 \% \\
1,415\end{array}$ & $\begin{array}{l}50 \% \\
1,183\end{array}$ & $\begin{array}{l}46 \% \\
1,131\end{array}$ & $\begin{array}{l}44 \%, \\
972\end{array}$ \\
\hline Completed F2 & $\begin{array}{l}10 \%, \\
237\end{array}$ & $\begin{array}{l}16 \%, \\
406\end{array}$ & $\begin{array}{l}20 \%, \\
536\end{array}$ & $\begin{array}{l}25 \% \\
693\end{array}$ & $\begin{array}{l}28 \% \\
765\end{array}$ & $\begin{array}{l}29 \% \\
769\end{array}$ & $\begin{array}{l}33 \% \\
834\end{array}$ & $\begin{array}{l}38 \% \\
879\end{array}$ & $\begin{array}{l}42 \% \\
1,032\end{array}$ & $\begin{array}{l}43 \%, \\
951\end{array}$ \\
\hline Current specialty trainee & $\mathrm{n} / \mathrm{a}$ & $\mathrm{n} / \mathrm{a}$ & $n / a$ & $\mathrm{n} / \mathrm{a}$ & $\mathrm{n} / \mathrm{a}$ & $\mathrm{n} / \mathrm{a}$ & $\mathrm{n} / \mathrm{a}$ & $\begin{array}{l}1 \%, \\
26\end{array}$ & $\begin{array}{l}1 \% \\
22\end{array}$ & $\begin{array}{l}2 \% \\
40\end{array}$ \\
\hline Alternative certificate $^{a}$ & $\begin{array}{l}7 \% \\
177\end{array}$ & $\begin{array}{l}8 \% \\
208\end{array}$ & $\begin{array}{l}11 \% \\
286\end{array}$ & $\begin{array}{l}8 \% \\
229\end{array}$ & $\begin{array}{l}9 \% \\
234\end{array}$ & $\begin{array}{l}10 \% \\
275\end{array}$ & $\begin{array}{l}11 \%, \\
261\end{array}$ & $\begin{array}{l}11 \%, \\
255\end{array}$ & $\begin{array}{l}11 \% \\
263\end{array}$ & $\begin{array}{l}11 \% \\
235\end{array}$ \\
\hline
\end{tabular}

${ }^{a}=$ none of the above, most commonly applicants from non-UK medical schools, in which case an alternative certificate for foundation competence is required; $F 2=$ foundation year 2 . 
Fig 1. Percentage completing MRCP(UK) Part 1 at time of application compared with applying after completing foundation. MRCP(UK) Part $1=$ Membership of the Royal Colleges of Physicians of the United Kingdom Part 1 examinations.

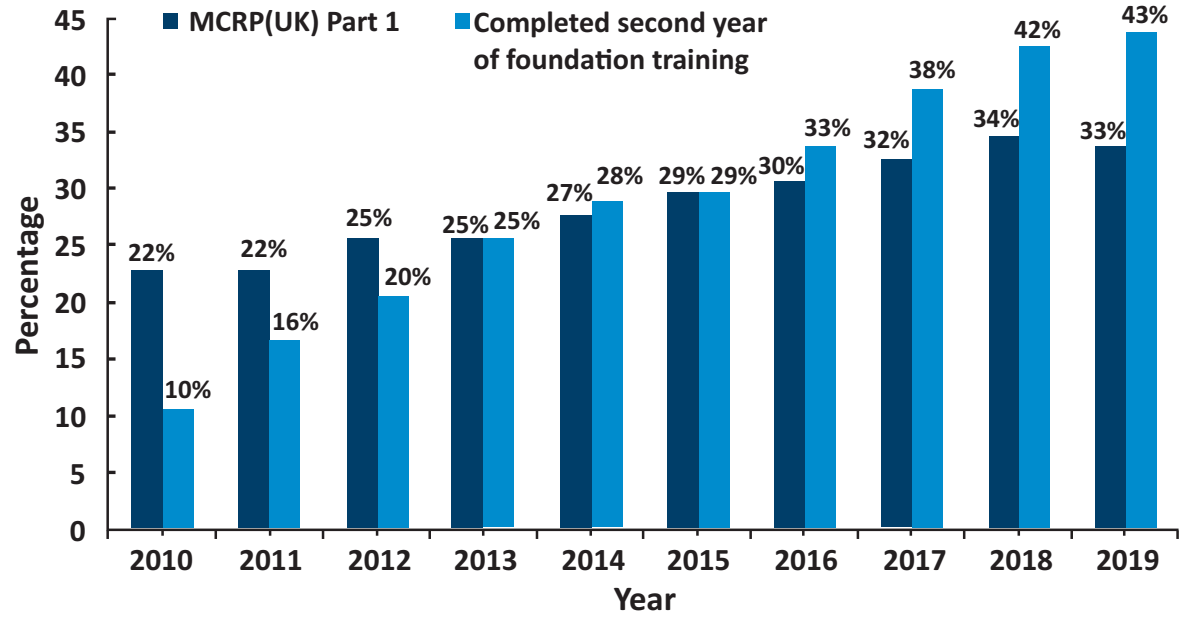

Equally concerning is that following the recent cohorts out as far as 6-years post normal CMT completion, the highest conversion rate into ST3+ trainees is $64.7 \%$ from the 2014 cohort with all years appearing to plateau out around $60 \%$. Thus, in summary the recruitment of doctors in the UK at the current time into CMT and ACCS-AM (and now IMT) appears to be generating about 960 higher medical specialty trainees each year if the current conversion and transition rates continue.

\section{Discussion}

Two recent reports to coincide with the 70th anniversary of the $\mathrm{NHS}$ set out the aspirations for the NHS as well as the challenges facing the service for the next decade. ${ }^{4,5}$ Not least the recruitment and retention of a workforce capable to deliver the improvements in healthcare declared in The NHS Long Term Plan. ${ }^{4}$ Both reports emphasise the need to expand the current workforce encompassing nursing, medical and allied healthcare professional roles.

More specifically, The NHS Long Term Plan promotes the expansion of UK medical school places by $25 \%$ up to 7,500 per year and reiterates ideas from the Shape of Training report in allowing trainees greater flexibility in switching specialties, and training a medical workforce better equipped to deal with an ageing population with multiple comorbidities. ${ }^{3,4}$ While the expansion in medical school numbers is welcome, many commentators including the Medical Workforce Unit of the RCP (informal communication) feel this is insufficient to address the workforce crisis and have called for a doubling of UK medical school admission numbers. Furthermore, with many trainees opting for less than full-time (LTFT) training for at least part of their training, and then continuing to work LTFT as senior doctors, this $25 \%$ expansion may not increase the workforce numbers as hoped.

As previously mentioned, the training model originally proposed in the Shape of Training report suggests a 2-year foundation programme followed by $4-6$ years spent in broad-based specialty training with options for an allied academic training programme and a year spent in leadership or other relevant roles. ${ }^{3}$ This model promoted both hospital specialists and GPs gaining specialist registration in a seamless manner and doesn't take into account trainees taking time out of this career path. As PSRO data from 2010 onwards shows, increasingly UK trained applicants applying for CT1 posts in medicine are doing so having already completed a foundation programme rather than applying directly from the second foundation year. This is not unique to applicants to core medicine and the annual report from the UK Foundation Programme Office (UKFPO) in 2018 surveyed over 6,400 foundation year 2 (F2) doctors of whom only $37.7 \%$ declared they were moving directly into specialty training. ${ }^{6}$ Furthermore $14.4 \%$ of the cohort reported the intention of taking a career break at the end of $\mathrm{F} 2$.

The UKFPO report does not offer explanations for the fall in the percentage of trainees moving directly from $\mathrm{F} 2$ into specialty training programmes in the past few years, but does

Table 3. Number of first year core medical trainee posts available and filled 2014-19

\begin{tabular}{llllllllll} 
& Posts & \multicolumn{3}{c}{ Filled } & \multicolumn{5}{c}{ Percentage } \\
& CMT & ACCS & Total & CMT & ACCS & Total & CMT & ACCS & Total \\
$\mathbf{2 0 1 4}$ & 1,474 & 71 & 1,545 & 1,468 & 71 & 1,539 & $99.6 \%$ & $100 \%$ & $100 \%$ \\
$\mathbf{2 0 1 5}$ & 1,544 & 65 & 1,609 & 1,494 & 64 & 1,558 & $96.8 \%$ & $98.5 \%$ & $96.8 \%$ \\
$\mathbf{2 0 1 6}$ & 1,634 & 76 & 1,710 & 1,492 & 76 & 1,560 & $91.5 \%$ & $100 \%$ & $91.2 \%$ \\
$\mathbf{2 0 1 7}$ & 1,656 & 60 & 1,716 & 1,469 & 60 & 1,530 & $88.8 \%$ & $100 \%$ & $89.2 \%$ \\
$\mathbf{2 0 1 8}$ & 1,670 & 57 & 1,727 & 1,610 & 56 & 1,666 & $96.4 \%$ & $98.2 \%$ & $96.5 \%$ \\
$\mathbf{2 0 1 9}$ & 1,520 & 63 & 1,583 & 1,520 & 63 & 1,583 & $100 \%$ & $100 \%$ & $100 \%$ \\
\hline ACCS = acute care common stem-acute medicine; CMT = core medical training (and internal medicine training in 2019). & \multicolumn{7}{c}{}
\end{tabular}




\begin{tabular}{|c|c|c|c|c|c|c|c|c|c|c|c|c|c|}
\hline \multirow{2}{*}{$\begin{array}{l}\text { Cohort } \\
2012\end{array}$} & \multirow{2}{*}{$\begin{array}{l}\text { Category } \\
\text { Core medical training }\end{array}$} & \multicolumn{2}{|c|}{1 year } & \multicolumn{2}{|c|}{2 years } & \multicolumn{2}{|c|}{3 years } & \multicolumn{2}{|c|}{4 years } & \multicolumn{2}{|c|}{5 years } & \multicolumn{2}{|c|}{6 years } \\
\hline & & 214 & $12.8 \%$ & 33 & $2.0 \%$ & 10 & $0.6 \%$ & 3 & $0.2 \%$ & 2 & $0.1 \%$ & 1 & $0.1 \%$ \\
\hline & General practice & 94 & $5.6 \%$ & 138 & $8.2 \%$ & 161 & $9.6 \%$ & 131 & $7.8 \%$ & 98 & $5.8 \%$ & 73 & $4.4 \%$ \\
\hline & Higher medicine & 711 & $42.4 \%$ & 897 & $53.5 \%$ & 954 & $56.9 \%$ & 939 & $56.0 \%$ & 991 & $59.1 \%$ & 819 & $48.8 \%$ \\
\hline & Not in training ${ }^{a}$ & 552 & $32.9 \%$ & 458 & $27.3 \%$ & 389 & $23.2 \%$ & 442 & $26.3 \%$ & 419 & $25.0 \%$ & 323 & $19.2 \%$ \\
\hline & Other specialties $^{b}$ & 106 & $6.3 \%$ & 151 & $9.0 \%$ & 163 & $9.7 \%$ & 161 & $9.6 \%$ & 165 & $9.8 \%$ & 145 & $8.6 \%$ \\
\hline & Completed training & 1 & $0.1 \%$ & 1 & $0.1 \%$ & 1 & $0.1 \%$ & 2 & $0.1 \%$ & 3 & $0.2 \%$ & 317 & $18.9 \%$ \\
\hline & Total candidates & 1,678 & & & & & & & & & & & \\
\hline \multirow[t]{7}{*}{2013} & Core medical training & 185 & $12.0 \%$ & 32 & $2.1 \%$ & 14 & $0.9 \%$ & 3 & $0.2 \%$ & 1 & $0.1 \%$ & & \\
\hline & General practice & 84 & $5.5 \%$ & 133 & $8.7 \%$ & 164 & $10.7 \%$ & 123 & $8.0 \%$ & 88 & $5.7 \%$ & & \\
\hline & Higher medicine & 656 & $42.7 \%$ & 842 & $54.8 \%$ & 887 & $57.7 \%$ & 934 & $60.8 \%$ & 911 & $59.3 \%$ & & \\
\hline & Not in training ${ }^{a}$ & 517 & $33.7 \%$ & 401 & $26.1 \%$ & 328 & $21.4 \%$ & 328 & $21.4 \%$ & 260 & $16.9 \%$ & & \\
\hline & Other specialties ${ }^{b}$ & 93 & $6.1 \%$ & 127 & $8.3 \%$ & 142 & $9.2 \%$ & 147 & $9.6 \%$ & 140 & $9.1 \%$ & & \\
\hline & Completed training & 1 & $0.1 \%$ & 1 & $0.1 \%$ & 1 & $0.1 \%$ & 1 & $0.1 \%$ & 136 & $8.9 \%$ & & \\
\hline & Total candidates & 1,536 & & & & & & & & & & & \\
\hline \multirow[t]{7}{*}{2014} & Core medical training & 125 & $8.3 \%$ & 32 & $2.1 \%$ & 10 & $0.7 \%$ & 2 & $0.1 \%$ & & & & \\
\hline & General practice & 60 & $4.0 \%$ & 101 & $6.7 \%$ & 124 & $8.3 \%$ & 106 & $7.1 \%$ & & & & \\
\hline & Higher medicine & 656 & $43.6 \%$ & 864 & $57.5 \%$ & 948 & $63.1 \%$ & 972 & $64.7 \%$ & & & & \\
\hline & Not in training ${ }^{a}$ & 572 & $38.1 \%$ & 384 & $25.5 \%$ & 285 & $19.0 \%$ & 244 & $16.2 \%$ & & & & \\
\hline & Other specialties ${ }^{b}$ & 90 & $6.0 \%$ & 122 & $8.1 \%$ & 136 & $9.0 \%$ & 144 & $9.6 \%$ & & & & \\
\hline & Completed training & 0 & $0.0 \%$ & 0 & $0.0 \%$ & 0 & $0.0 \%$ & 35 & $2.3 \%$ & & & & \\
\hline & Total candidates & 1,503 & & & & & & & & & & & \\
\hline \multirow[t]{7}{*}{2015} & Core medical training & 157 & $10.3 \%$ & 26 & $1.7 \%$ & 7 & $0.5 \%$ & & & & & & \\
\hline & General practice & 54 & $3.6 \%$ & 98 & $6.4 \%$ & 125 & $8.2 \%$ & & & & & & \\
\hline & Higher medicine & 612 & $40.2 \%$ & 864 & $56.8 \%$ & 945 & $62.1 \%$ & & & & & & \\
\hline & Not in training ${ }^{a}$ & 618 & $40.6 \%$ & 416 & $27.4 \%$ & 301 & $19.8 \%$ & & & & & & \\
\hline & Other specialties ${ }^{b}$ & 78 & $5.1 \%$ & 115 & $7.6 \%$ & 134 & $8.8 \%$ & & & & & & \\
\hline & Completed training & 2 & $0.1 \%$ & 2 & $0.1 \%$ & 9 & $0.6 \%$ & & & & & & \\
\hline & Total candidates & 1,521 & & & & & & & & & & & \\
\hline \multirow[t]{7}{*}{2016} & Core medical training & 114 & $7.2 \%$ & 26 & $1.6 \%$ & & & & & & & & \\
\hline & General practice & 46 & $2.9 \%$ & 97 & $6.1 \%$ & & & & & & & & \\
\hline & Higher medicine & 603 & $37.9 \%$ & 880 & $55.3 \%$ & & & & & & & & \\
\hline & Not in training ${ }^{a}$ & 749 & $47.0 \%$ & 469 & $29.5 \%$ & & & & & & & & \\
\hline & Other specialties ${ }^{b}$ & 80 & $5.0 \%$ & 119 & $7.5 \%$ & & & & & & & & \\
\hline & Completed training & 0 & $0.0 \%$ & 1 & $0.1 \%$ & & & & & & & & \\
\hline & Total candidates & 1,592 & & & & & & & & & & & \\
\hline \multirow[t]{7}{*}{2017} & Core medical training & 112 & $7.5 \%$ & & & & & & & & & & \\
\hline & General practice & 40 & $2.7 \%$ & & & & & & & & & & \\
\hline & Higher medicine & 487 & $32.6 \%$ & & & & & & & & & & \\
\hline & Not in training ${ }^{a}$ & 763 & $51.1 \%$ & & & & & & & & & & \\
\hline & Other specialties ${ }^{\mathrm{b}}$ & 90 & $6.0 \%$ & & & & & & & & & & \\
\hline & Completed training & 0 & $0.0 \%$ & & & & & & & & & & \\
\hline & Total candidates & 1,492 & & & & & & & & & & & \\
\hline
\end{tabular}

${ }^{a}=$ encompasses a broad range of possibilities including trust posts, being overseas or in research; ${ }^{b}=$ any other non-medicine specialty, except general practice. 
report that this decision reflects a change in trainees' attitudes given that $49.7 \%$ of the 2018 cohort suggested they would move straight into specialty training when asked at the start of foundation year 1 (F1). ${ }^{6}$ However, some insight is available from a 2017 British Medical Association (BMA) survey of over 2,150 trainees (at various stages in their training and $18 \%$ of whom were in a medical specialty) examining different trends including reasons for taking a career break. ${ }^{7}$ Fifty-six per cent of this cohort reported having taken one or more breaks in their clinical training. Trainees could give multiple reasons for taking a break and one in four highlighted a desire to travel, or for maternity or paternity leave. Equally, one in five mentioned taking a nontraining post or working as a locum as the rationale for a break in training.

Does a career break matter? The BMA survey suggests that the majority of those taking a career break are still working as doctors widening their experience. Furthermore, anecdotally the experience of the authors of this paper is that many trainees use these opportunities to enhance their job prospects in subsequent recruitment rounds by demonstrating growth in the breadth of their competencies.

The apparent 'spike' in unique applicants for CMT posts in 2018 could be related to this being the last year of the established CMT programme, and trainees opting to enrol in a familiar programme rather than the new IMT curriculum being introduced in 2019.

The major challenge for medical specialties is to convert applications and recruitment into CT1 into sufficient ST3 applications in medical specialties. Table 4 highlights that the current numbers coming through CMT/IMT (between 1,500-1,600 per year) are only generating about 960 trainees per year in ST3+ medical specialties. Although a percentage choose other specialties such as GP or clinical oncology, the numbers coming through CMT/IMT are insufficient to fill the approximate 1,200 ST3 posts on offer in round 1 alone each year in the 24 (and one sub-) medical specialties covered by the PSRO (data from the PSRO). Moreover, this number of ST3 trainees is insufficient to fill the current number of vacancies at consultant level; indeed recent data from the Medical Workforce Unit of the RCP highlighted that $45 \%$ of advertised consultant physician posts in the UK in 2018 were unfilled because of a lack of suitable applicants. ${ }^{8}$ Such vacancy rates will limit efforts to deliver many of the aspirations of The NHS Long Term Plan. ${ }^{4}$

The difficulties in recruiting sufficient trainees in medical specialties have been explored previously with questionnaires sent to over 3,000 F2, CMT and ST3+ stage trainees. ${ }^{9}$ The F2 and CMT level trainees reported that the clinical case mix, academic challenge and working within a team structure were attractions to a career in a medical specialty, but the overriding deterring factor was the perceived work-life balance as a medical registrar. Equally over $30 \%$ of the ST $3+$ respondents reported considering giving up the general internal medicine part of their dual accreditation in the preceding 6 months (and this was nearly double the percentage having similar thoughts about their main specialty) in part because of the same reason.

At the same time, the RCP published two reviews highlighting the workload of medical registrars and proposed ideas working with other educational stakeholders to improve recruitment and retention of this cohort of doctors as well as measures to maximise doctors' effectiveness. ${ }^{10,11}$ Subsequently, measures such as the chief registrar scheme have been introduced and flexible portfolio training is being piloted from August 2019. ${ }^{12,13}$ Both of these schemes aim to allow medical registrars protected time to develop professional skills in areas such as leadership, research, medical education or quality improvement.

Another reported challenge is the complexity of the transition from CMT to medical registrar, with only $70 \%$ of UK trainees undertaking or managing to complete all parts of $\mathrm{MRCP}(\mathrm{UK})$ by the end of CT2 (informal communication with MRCP(UK) unit). To help address both these issues the new IMT curriculum will deliver a much more supportive transition to the role of medical registrar and provide support to complete all parts of MRCP(UK) within an ongoing training programme. ${ }^{14}$

The recruitment data from the PSRO highlights that insufficient trainees are choosing a CMT/IMT career to allow enough to flow through to ST3 medical specialty recruitment and, ultimately, fill the vacancy rates in consultant physician posts in the UK. Measures such as the chief registrar scheme to enhance the attractiveness of medical specialties are clearly vital-not least for the wellbeing of the current incumbents, and the new IMT programme may help with numbers. However, in the medium and longer term, a greater pool of potential applicants will be needed. In the last few years despite increasing numbers of CMT and ST3 posts on offer each year, the number of trainees coming through has stayed relatively constant. A radical rethink of UK medical school numbers will be required to change not only the recruitment situation in medical specialties, but similar crises in other understaffed specialties (not least GP and psychiatry) seeking to expand their workforce numbers.

\section{References}

1 NHS. IMT Recruitment. NHS, 2019. www.imtrecruitment.org.uk [Accessed 19 July 2019].

2 General Medical Council. Summary of medical schools 2014 annual return. GMC, 2015. www.gmc-uk.org/-/media/documents/ medical-school-annual-return-2014-summary-report-for-publication-61816122_pdf-62533230.pdf [Accessed 19 July 2019].

3 Shape of Training. Securing the future of excellent patient care: Final report of the independent review. Shape of Training, 2013. www.shapeoftraining.co.uk/static/documents/content/Shape of_training_FINAL_Report.pdf_53977887.pdf [Accessed 19 ]uly 2019].

4 NHS. The NHS Long Term Plan. NHS, 2019. www.longtermplan.nhs. uk/wp-content/uploads/2019/01/nhs-long-term-plan-june-2019. pdf [Accessed 19 July 2019].

5 Beech J, Bottery S, Charlesworth A et al. Closing the gap: Key areas for action on the health and care workforce. Nuffield Trust, 2019. www.nuffieldtrust.org.uk/files/2019-03/heaj6708-workforce-fullreport-web.pdf [Accessed 19 July 2019].

6 UK Foundation Programme Office. F2 career destinations report 2018. NHS, 2018. www.foundationprogramme.nhs.uk/sites/default/ files/2019-01/F2\% 20Career \% 20Destinations \% 20Report_FINAL. pdf [Accessed 19 July 2019].

7 British Medical Association. Understanding trends among current doctors in training. BMA, 2018. www.bma.org.uk/collective-voice/ policy-and-research/education-training-and-workforce/juniorscareer-survey [Accessed 19 July 2019].

8 Royal College of Physicians. Focus on physicians: Census of physicians and higher specialty trainees 2017-18. London: RCP, 2018. www.rcplondon.ac.uk/projects/outputs/focus-physicians2017-18-census-uk-consultants-and-higher-specialty-trainees [Accessed 19 July 2019].

9 Chaudhuri E, Mason NC, Newbery N, Goddard AF. Career choices of junior doctors: in the physician an endangered species? Clin Med 2013;13:330-5. 
10 Royal College of Physicians. The medical registrar: Empowering the unsung heroes of patient care. London: RCP, 2013. www.rcplondon. ac.uk/guidelines-policy/hospital-workforce-fit-future [Accessed 19 July 2019].

11 Royal College of Physicians. Hospital workforce: Fit for the future? London: RCP, 2013. www.rcplondon.ac.uk/guidelines-policy/ hospital-workforce-fit-future [Accessed 19 July 2019].

12 Royal College of Physicians. Chief registrar scheme. London: RCP, 2019. www.rcplondon.ac.uk/projects/chief-registrar-scheme [Accessed 19 July 2019].

13 Royal College of Physicians. Flexible portfolio training. London: RCP, 2019. www.rcplondon.ac.uk/projects/flexible-portfolio-training [Accessed 19 July 2019].
14 Joint Royal Colleges of Physicians Training Board. Curriculum for Internal Medicine Stage 1 Training. JRCPTB, 2019. www.jrcptb. org.uk/sites/default/files/IM \% 20stage \% 201\% 20curriculum \% 20 FINAL \% 20100519.pdf [Accessed 19 ]uly 2019].

Address for correspondence: Dr Richard Butterworth, Milton Keynes University Hospitals NHS Trust, Neurology, Standing Way, Milton Keynes, Buckinghamshire MK6 5LD, UK.

Email: richard.butterworth@mkuh.nhs.uk

\section{Royal College} of Physicians

\section{Looking for jobs in medicine?} Find your next hospital job

Find out more and subscribe to the monthly Medicine Jobs bulletin at www.rcplondon.ac.uk/jobsboard 